\title{
Improved Convenient Synthesis of Benzoyl Metronidazole: A Nitroimidazole Antibiotics
}

\author{
Zhi-zhong Wang, Long Wang, and Pei Huang \\ Ningxia Engineering Research Center for Hui Medicine Modernization, School of Pharmacy, Ningxia Medical University, \\ Yinchuan, Ningxia 750004, China
}

Correspondence should be addressed to Zhi-zhong Wang; wangzzsc@yahoo.com

Received 22 June 2012; Revised 7 August 2012; Accepted 23 August 2012

Academic Editor: Casimiro Mantell

Copyright (c) 2013 Zhi-zhong Wang et al. This is an open access article distributed under the Creative Commons Attribution License, which permits unrestricted use, distribution, and reproduction in any medium, provided the original work is properly cited.

An improved, cost-effective, and one-pot method for the synthesis of benzoyl metronidazole was achieved by using $N, N^{\prime}$ carbonyldiimidazole as a coupling reagent. Moreover, the byproduct imidazole as the catalyst promoted the reaction. The procedures are simple and suitable to large-scale manufactures.

\section{Introduction}

Metronidazole (MTZ), 1-hydroxyethyl-2-methyl-5-nitroimidazole, is known to be a powerful antiprotozoal and antibacterial drug. It is clinically effective in trichomoniasis, amoebic colitis, and giardiasis [1]. However, it has a bitter taste, and it is not acceptable to some young patients. Benzoyl metronidazole, the benzoyl ester of metronidazole, is tasteless and has also been widely used because of its greater palatability [2].

The conventional routes for synthesis of benzoyl metronidazole were the two-step synthesis as shown in Scheme 1 , which required the preparation of benzoyl chloride, the reaction required strict anhydrous conditions [3, 4], and the reactor should be corrosion resistant. In addition, in the combination of benzoyl chloride and metronidazole, the deacid reagent such as pyridine was needed to promote the reaction. $N, N^{\prime}$-carbonyldiimidazole (CDI) is one of several commonly used reagents for activating carboxyl groups. It is relatively cheap, and the only byproducts are carbon dioxide and imidazole which, being relatively benign, are unlikely to cause problems on scale up [5]. Herein, we report an improved procedure for the preparation of benzoyl metronidazole in one pot by using $N, N^{\prime}$-carbonyldiimidazole as a coupling reagent, and the byproduct imidazole as the catalyst can promote the reaction. These processes are simple and suitable to large-scale manufactures (Scheme 2).

\section{Experimental}

The HPLC assays for the purity of benzoyl metronidazole were performed on a Perkin-Elmer Series 200 HPLC system using a Kromasil 100-10-C18 column $(4.6 \mathrm{~mm} \times 250 \mathrm{~mm})$ at room temperature; flow rate: $1.0 \mathrm{~mL} / \mathrm{min}$; detection wavelength: $310 \mathrm{~nm}$; the mobile phase: $35: 65 \mathrm{MeOH}-\mathrm{KH}_{2} \mathrm{PO}_{4}$ $(0.02 \mathrm{M})$. The melting point determinations were carried out on an XRC-1 melting point apparatus. The progresses of the reactions were monitored by TLC on $0.25 \mathrm{~mm}$ thick layers of silica gel $\mathrm{GF}_{254}$ developed with solvent system, AcOEt: petroleum ether $(1: 1 \mathrm{v} / \mathrm{v})$. Dichloromethane (DCM) was dried by $\mathrm{CaCl}_{2}$ for $12 \mathrm{~h}$ and distilled prior to use. All other chemicals were of commercial grade and used without further purification.

2.1. General Experimental Procedure. To a solution of benzoic acid $(100.0 \mathrm{~g}, 820 \mathrm{mmoL})$ in $4 \mathrm{~L}$ anhydrous DCM, $N, N^{\prime}$ carbonyldiimidazole ( $160.0 \mathrm{~g}, 984 \mathrm{mmoL}$ ) was added at room temperature. After stirred for $8 \mathrm{~h}$, metronidazole ( $140 \mathrm{~g}$, $820 \mathrm{mmoL}$ ) in $10 \mathrm{~L}$ anhydrous DCM was added. Then, the resulting solution was refluxed for $16 \mathrm{~h}$ and concentrated. The residue was dissolved in $8 \mathrm{~L} \mathrm{DCM}$, and sequently washed with $1 \mathrm{M}$ sodium carbonate solution $(2 \times 1.5 \mathrm{~L}), 10 \% \mathrm{HCl}(2 \times 1.0 \mathrm{~L})$, distilled water $(3 \times 1.5 \mathrm{~L})$. The organic layer was separated, dried over anhydrous sodium sulphate, and concentrated in vacuo. Finally, the concentrate was crystallized from ethanol 


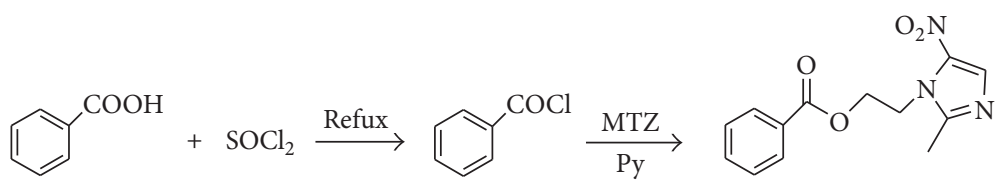

Scheme 1: The conventional routes.

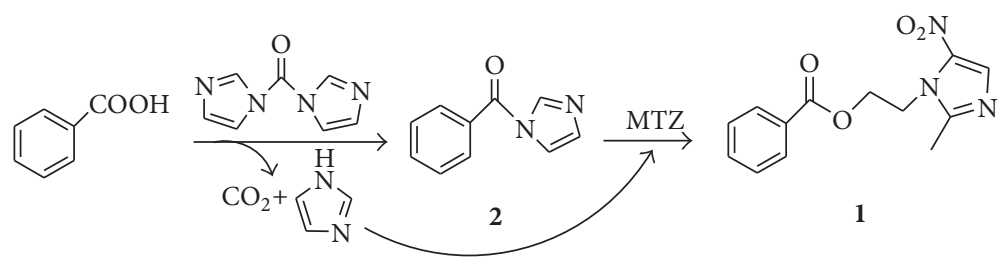

SCHEME 2: The improved convenient procedures.

to give 1 (190.2 g). Yield 84.3\%; M.p.: $99.6-100.8^{\circ} \mathrm{C}$ ([6] 99-102 $\left.{ }^{\circ} \mathrm{C}\right)$. Purity $98.7 \%$ by HPLC (UV).

\section{Results and Discussion}

In our work, we found that simply mixing benzoyl imidazole (2) with metronidazole in DCM did not result in an obvious reaction in $24 \mathrm{~h}$. Imidazole can efficiently promote the reaction. Furthermore, the stronger bases such as $\mathrm{Na}_{2} \mathrm{CO}_{3}$ or $\mathrm{Et}_{3} \mathrm{~N}$ did not distinctly enhance the reaction rate.

$N, N^{\prime}$-carbonyldiimidazole is a useful, general carboxylic acid activating reagent, and its byproduct imidazole can serve as the catalyst. Therefore, benzoyl metronidazole (1) was prepared in a simple, two-step sequence in just one reactor. In the first step, based on TLC analysis, the reaction between benzoic acid and $N, N^{\prime}$-carbonyldiimidazole was quantitative within $8 \mathrm{~h}$ at room temperature. In the second step, the coupling of metronidazole to the benzoyl group was accomplished in $16 \mathrm{~h}$ under reflux in DCM.

The optimized conditions for the synthesis of benzoyl metronidazole are benzoic acid/N, $N^{\prime}$-carbonyldiimidazole/ metronidazole $=1 / 1.2 / 1(\mathrm{moL} / \mathrm{moL})$. The purity and structure were confirmed by TLC, HPLC, and Melting point.

\section{Conclusions}

An improved method for the preparation of benzoyl metronidazole via a one-pot reaction was developed by using $N, N^{\prime}$ carbonyldiimidazole as a coupling reagent, which do not require extra catalysts. Compared with routine synthetic methods, these procedures may become an efficient route for the synthesis of benzoyl metronidazole on a large scale.

\section{Acknowledgments}

Financial supports from the Natural Science Foundation of Ningxia (no. NZ11110) and the Undergraduate Innovation
Project of Ningxia Medical University are gratefully acknowledged.

\section{References}

[1] T. J. Mehta, M. Mothilal, M. R. Patel, K. R. Patel, A. D. Patel, and N. M. Patel, "Formulation, development and optimization of metronidazole compression coated tablets," Der Pharmacia Lettre, vol. 3, no. 5, pp. 94-103, 2011.

[2] T. V. Nicole, A. Vasileios, J. B. Michel et al., "Stability of metronidazole benzoate in SyrSpend SF one-step suspension system," International Journal of Pharmaceutical Compounding, vol. 12, no. 6, pp. 558-564, 2008.

[3] S. Dubey, V. Jain, and G. B. Preethi, "Evaluation of lipophilicity, antimicrobial activity and mutagenicity of some novel ester prodrugs of metronidazole," Indian Journal of Chemistry B, vol. 48, no. 11, pp. 1571-1576, 2009.

[4] M. Johansen and C. Larsen, "A comparison of the chemical stability and the enzymatic hydrolysis of a series of aliphatic and aromatic ester derivatives of metronidazole," International Journal of Pharmaceutics, vol. 26, no. 3, pp. 227-241, 1985.

[5] E. K. Woodman, J. G. K. Chaffey, P. A. Hopes, D. R. J. Hose, and J. P. Gilday, "N,N'-carbonyldiimidazole-mediated amide coupling: significant rate enhancement achieved by acid catalysis with imidazole · HCI," Organic Process Research and Development, vol. 13, no. 1, pp. 106-113, 2009.

[6] EDQM, European Pharmacopoeia 7.0, metronidazole benzoate, 2008. 

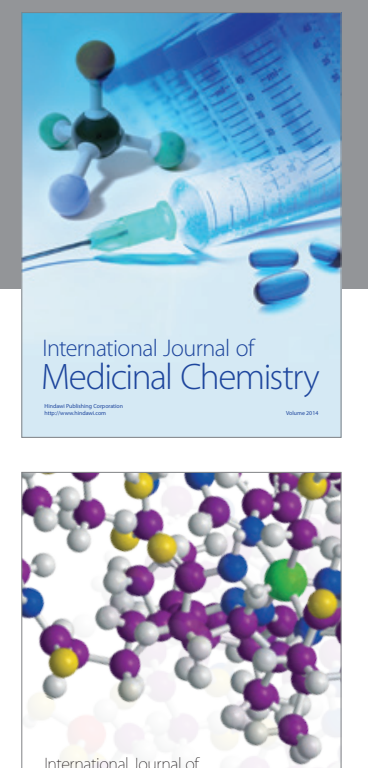

\section{Carbohydrate} Chemistry

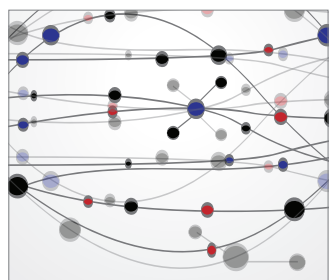

The Scientific World Journal
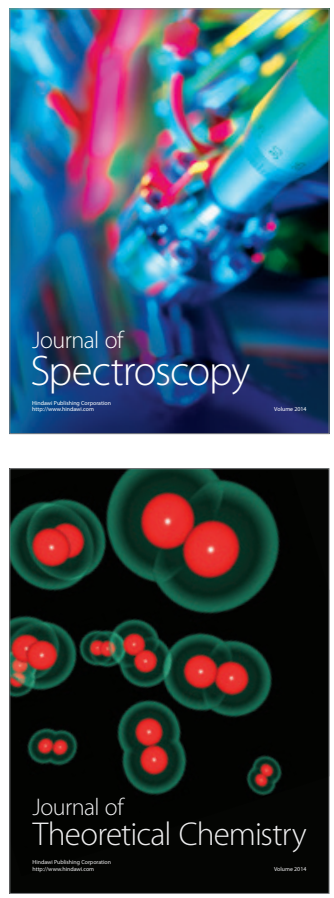
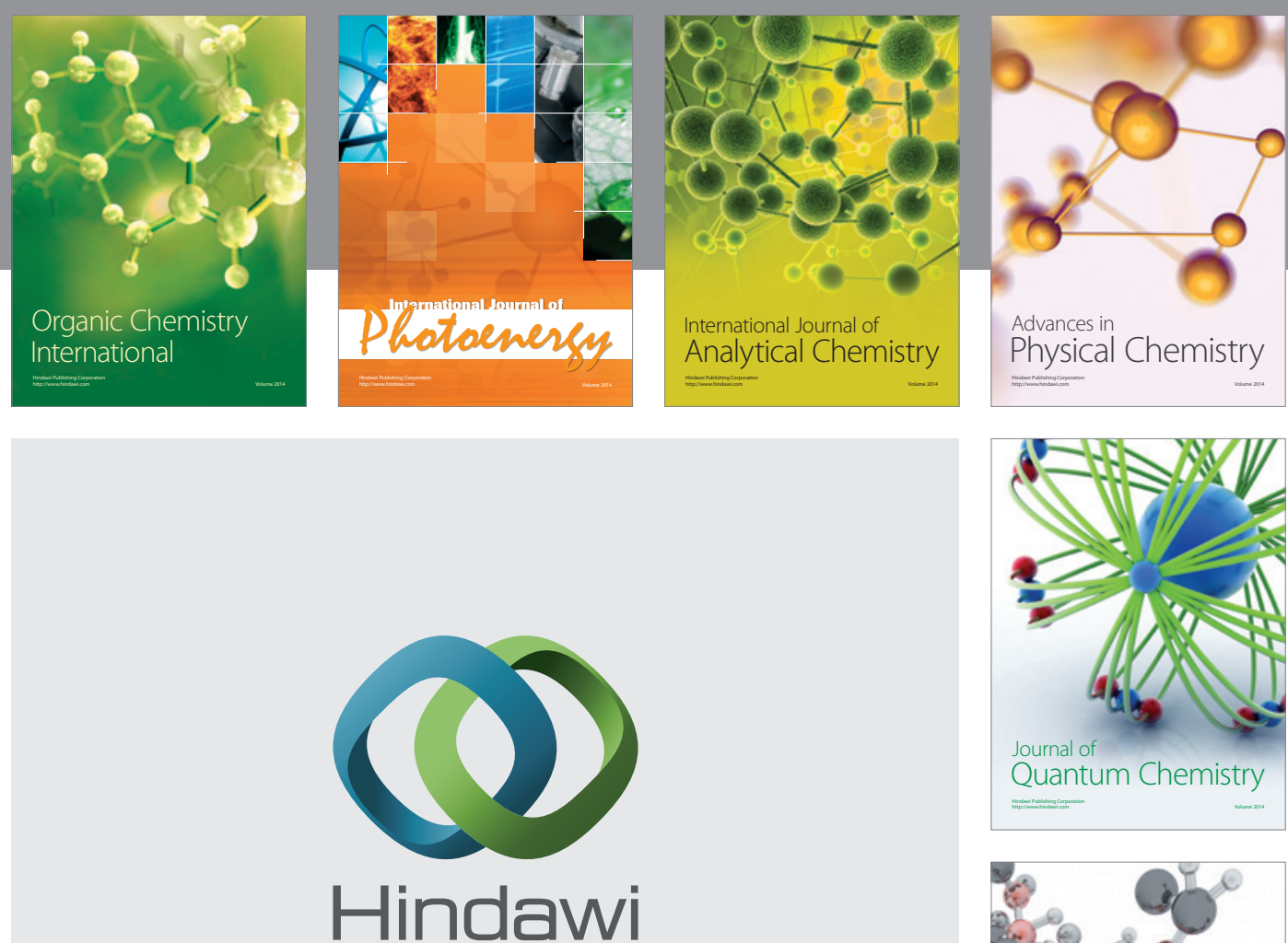

Submit your manuscripts at

http://www.hindawi.com

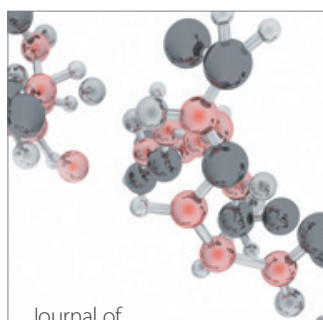

Analytical Methods

in Chemistry

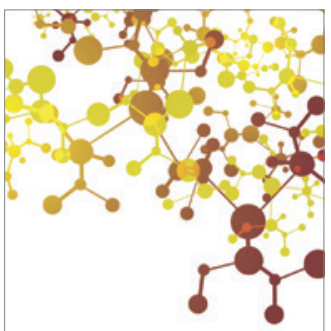

Journal of

Applied Chemistry

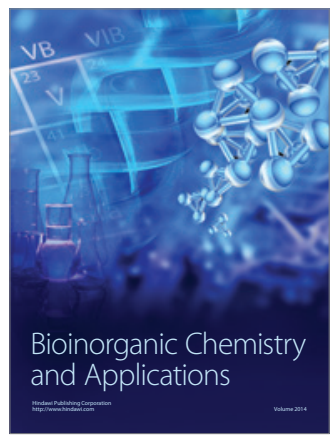

Inorganic Chemistry
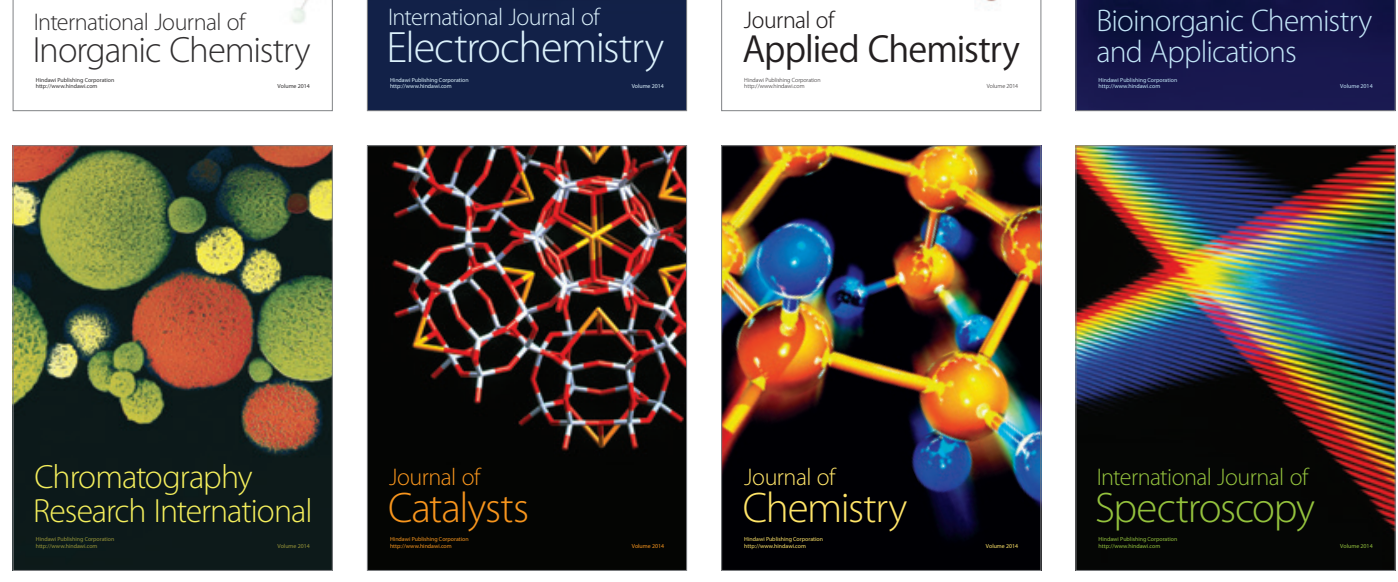